\title{
Research on Sense of Fulfillment, Happiness and Security of Talents in New Era
}

\author{
Yunna Liu ${ }^{1,2, *}$, Hao Wang ${ }^{1}$ \\ ${ }^{1}$ School of Management, Tianjin University of Technology, Tianjin, China \\ ${ }^{2}$ College of Management and Economics, Tianjin University, Tianjin, China \\ *Corresponding Author: Yunna Liu
}

\begin{abstract}
:
This research chooses the talents of the new era as the research object and the sense of fulfillment, happiness and security as the foothold. Through the research on the sense of fulfillment, happiness and security of the talents in the new era, the paper demonstrates talents how to make a good career planning and development, so as to improve the quantity and quality of employment. After consideration of the relationship between the sense of fulfillment, happiness, and security of talents, the paper illustrates talents should cognize the overall status of career development, increase self-awareness of values, interest and skills, know the occupation choices and understand the industry in New Era.
\end{abstract}

Keywords: New era, Talents, Sense of fulfillment, Sense of happiness, Sense of security.

\section{INTRODUCTION}

China puts forward that the sense of people's fulfillment, happiness and security should be enriched, guaranteed and sustainable [1]. At the same time, the sense of fulfillment, happiness and security also reflects that the China can better meet the expectations of the people in the new era. People hope to live a better life of high quality. The good life demanded by the common people requires not only a high standard of material culture, but also democracy, the rule of law, fairness, justice, security, environment and other aspects [2].

There are different meanings in sense of fulfillment, sense of happiness and sense of security, but they are closely related. In terms of people's demands for a better life, there are differences in quantity and quality of happiness. In terms of perception, the two are both intersecting and different. On the one hand, people need more acquisitions, and happy life will lose its foundation without material and cultural acquisition; on the other hand, acquisition and happiness are not directly corresponding. The number of acquisition is not equal to a high happiness index, and whether life is happy is not determined by the number of acquisitions. The sense of security guarantees the sense of fulfillment and happiness. Without security as a 
guarantee, there is a danger of losing as well as gaining more; without security as a guarantee, there is no way to talk about happiness in life. With the fulfillment and pursuit of happiness, there must be a demand for security. At the same time, people's sense of fulfillment, happiness and security in the new era is more substantial and more secure.

\section{SENSE OF FULFILLMENT OF TALENTS IN NEW ERA}

The "sense of fulfillment" is actually a sense of satisfaction in accomplishing a thing [3]. It is not only embodied in material, but also in spirit. Talents in the new era are closely linked with the development of society in terms of personal growth conditions, development opportunities and responsibilities. Everyone's ideal and pursuit should not be limited to their own, but for the consideration of the society as a large family. So that is to say, in the new era, talents should associate their personal ideals with social ideals, so as to magnify their sense of personal gain. At the present stage in China, the construction and development of China fully reflects the broadest common aspirations, interests and requirements, and is the common ideal pursued unremittingly. Only by organically combining personal development with this common ideal can the talents in the new era find their own life orientation. Starting from oneself, from now on, they are diligent in reading and practice, constantly improve their scientific and cultural qualities and ideological qualities, and enhance their sense of fulfillment to the national level.

\section{SENSE OF HAPPINESS OF TALENTS IN NEW ERA}

The "happiness" refers to a series of joys and pleasures that people produce subjectively based on their own sense of satisfaction and security [4]. It's not easy for a person to succeed. People only see successors' happiness after success, but they don't realize the hardships successors have to pay in the process of success [5]. Once a link fails, they will miss the success and the happiness they pursue will disappear. According to the research, the happiness of talents in the new era is controlled by many subjective and objective factors.

\subsection{Objective Factors}

\subsubsection{Social Support}

People with social support are better able to get material or spiritual help in order to gain a sense of belonging and self-esteem. When they encounter emergency events, they can respond in a timely manner, increase positive emotions, and bring a sense of non-panic. This study shows that the well-being of talents in the new era is positively correlated with social support.

\subsubsection{Culture}

There are different understandings of happiness under the different cultural backgrounds between the East and the West. This study shows that culture has a significant impact on values, self, happiness, emotional arousal and other variables.

\subsubsection{Demographic Variables}

Researchers believe that individual happiness increases with age. Gender divides people into different groups in physiological, psychological and social functions. Gender has no 
significant difference in happiness, but there are some differences in positive and negative emotions.

\subsection{Subjective Factors}

\subsubsection{Personality}

Happiness is more determined by one's own personality, the most prominent feature of which is subjectivity. Therefore, personality characteristics become the most powerful and core factor affecting subjective well-being. Happiness research found that both ability selfperception and personality are related to well-being.

\subsubsection{Self-efficacy and Self-esteem}

Self-efficacy refers to people's subjective judgment on whether they can succeed in a certain achievement behavior. Self-esteem has a strong predictive effect on individual's subjective wellbeing. The study found that the higher the implicit self-esteem, the higher the subjective wellbeing level. In the low explicit self-esteem, the implicit self-esteem did not affect the subjective well-being of the individual. This study shows that subjective well-being and self-esteem of talents in the new era are significantly correlated.

\section{SENSE OF SECURITY OF TALENTS IN NEW ERA}

The sense of security is the psychological need for stability and security [6]. It belongs to the inner spiritual needs of individuals. Nowadays, with the rapid development of information, the pressure from the society is also increasing for the talents in the new era with high sensitivity. According to the research, the influencing factors of talent security in the new era can be divided into the following two aspects.

\subsection{Self-psychological Factors}

Gap between urban and rural areas, interpersonal relationships and personal personality are self-psychological factors affecting the sense of security of talents in the new era.

\subsection{Family Environment Factors}

\subsubsection{Single Parent}

The single parent situation caused by parents' marital status has a tremendous impact on the psychological status of the talents in the new era, and at the same time leads to the lack of their sense of security. Disharmonious family environment is also an important factor for personal security.

\subsubsection{Family Education Modes}

Parents of different educational levels have different choices for their children's education modes. Children who grow up under the parents' high pressure often lack a sense of security. Parents of different educational levels have different choices for their children's education modes. Children who grow up under the parents' high pressure often lack a sense of security. 


\section{CAREER DEVELOPMENT FOR ATTAINING SENSE OF FULFILLMENT, HAPPINESS AND SECURITY OF TALENTS IN NEW ERA}

In the new era, one of the ways for talents to attain a sense of fulfillment, happiness and security is to work hard, and the premise for them to work hard is to do what they like and suit themselves. If they want to choose the most suitable job, they should have a perfect career planning and development, so that they can have a greater sense of fulfillment, happiness and security.

With the development of the country, the supply of materials is abundant, the living standard and quality of the people have been greatly improved, and the cultural industry has been constantly developing. The people's sense of material and spiritual acquisition has been greatly satisfied. The achievements of the China reform provide the people a sense of fulfillment. At the same time, talents in new era also need to attain a sense of fulfillment through their own work. Choosing a job that suits them can help talents feel empowered. At the same time, talents are more likely to have a sense of happiness and security when their material and spiritual needs are met. The researcher suggests them follow the steps (see Figure 1) as following:

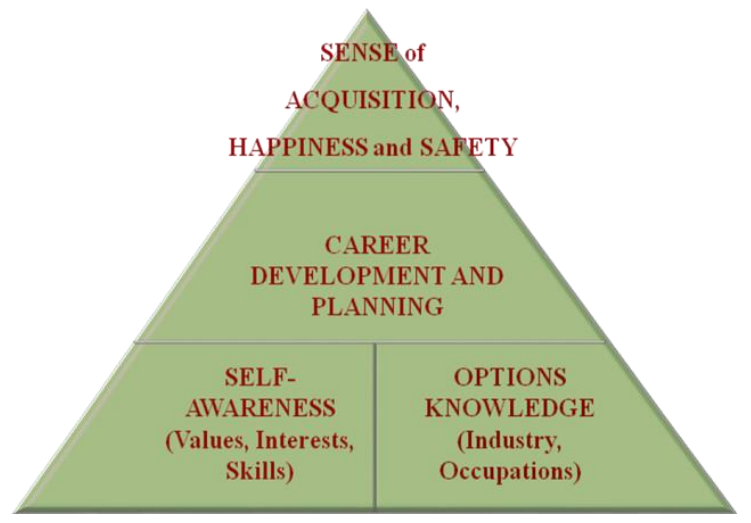

Fig 1: Career Development for Attaining Sense of Fulfillment, Happiness and Security.

\subsection{Cognize the Overall Status of Career in New Era}

Talents in the new era should first have a general understanding of their career in the new era before choosing a job. The nature of work is changing at this stage. People's career process is no longer limited to a job, but adjusts the career choice with the changes of their own development and society. Workplaces are becoming more diverse, and gender has less and less influence on job choices. More and more women are entering the labor market. This trend also forces people to look at the roles of men and women in the family more equally. In addition, more and more information and resources are available to help people make career plans. At the same time, people's quality of life is also affected by the health of the national economy, industry and institutions, and the methods employed by job seekers.

\section{$5.2 \quad$ Self-awareness}

\subsubsection{Values}

If talents can live according to their own values, they can get the maximum sense of 
happiness and freedom. At the same time, talents in new era should find out what their most important needs for a job. A job cannot meet all their needs, just as high income and stability are usually not possible to have both, then talents in new era need to find out what they want more.

\subsubsection{Interests}

In the process of career planning, talents in new era should take their interests as an important consideration. Interest is to be able to do something for the fun of doing something. Often, the area of interest will be the area where they are better at. It will be easier and happier to do the work they like and are better at, so that they can get a sense of fulfillment and happiness more easily.

\subsubsection{Skills}

When making career plans and choices, talents in new era should be clearer about their skills and know what they can do. General skills usually include communication, creativity, critical thinking, leadership, life management, social responsibility, teamwork, technical or scientific capabilities, and research project development capabilities. To find out what skills they possess, talents can better seek a career that can make full use of their skills, so that their self-worth can be fully realized and their sense of fulfillment and happiness can be enhanced. In the process of career choice, talents often encounter professions that meet their own values and interests, but their skills are not enough for this profession. Therefore, in the process of selfawareness, talents should know more about how to increase and expand their own skills, and create more possibilities for their career choice.

\subsection{Know the Occupation Choices}

In the new era, there are many choices for work. To live efficiently and wisely in such a complex global economic environment means that talents need to understand the choices in depth. Talents in new era should have a general understanding of the types and quantities of occupations which are not unchanged. They change and develop with the changes of the times. To choose a suitable job, talents need to have a good grasp of the development and changes of the occupations. Only when they have a deep understanding of the occupations they can choose, can they choose the ones they are most interested in, the most skilled and most suitable for their own career.

\subsection{Understand the Industry}

Understanding of the industry includes the way the industry works and the workplace, and the kind of industry and environment of the career. In view of the skills needed for choosing a career, talents should also train and strengthen the skills they need purposefully. In order to consolidate the relevant information of education and training of the skills needed, talents in new era should also have a deeper understanding of the changes and development of the times and industries. Talents in new era should strengthen industry related professional skills in order to make a suitable career planning and development, which leads to the sense of fulfillment, happiness and security in new era. 


\section{CONCLUSION}

People have more yearnings and demands for a better life in the new era. There are many differences in material and spiritual requirements. China is also working hard to meet people's demands and create a new society for the people in the new era. In the new era, the sense of fulfillment, happiness, and security of talents are not only different from each other, but also interrelated. These three senses not only depend on the external environment, but also on personal self-giving. Talents in new era should make a suitable career development and planning, including self-understanding in the process of decision-making, recognizing the overall situation of career in the new era, and choosing their suitable occupations and industries. Connecting one's own ideal with society, uniting the sense of fulfillment, happiness and security, and properly handling the relationship among them can better promote the overall development of individuals, the country and society.

\section{REFERENCES}

[1] People's Daily (2017) Available at http://cpc.people.com.cn/n1/2017/1028/c64094-29613660.html.

[2] Shao-Zhe Zhang, et al (2019) Study on the Influencing Factors of Urban Youth Health under the Background of a Better Life_—From the Perspective of Cultural Capital Theory. Journal of Harbin Institute of Technology.

[3] YAMAMOTO, Keizo (2010) Does cooperation with others bring about satisfaction? the structure of one's sense of fulfillment in occupational life. Soshioroji 55: 19-35, 129.

[4] Deguang Hu (2018) Continuously improving the sense of happiness and sense of security of the people. Heze Daily, Feb.10 (001).

[5] Xin-Cheng, Z (2015) Research on college students' sense of happiness in the perspective of communication theory: an empirical analysis of shaoguan university. Journal of Shaoguan University.

[6] Barbro Krevers, Anna Milberg (2015) The Sense of Security in Care-Relatives' Evaluation Instrument: Its Development and Presentation. Journal of Pain and Symptom Management 49(3). 